\title{
Towards a Perception of Computing Related Programmes Offered by Public Tertiary Institutions in Ghana
}

\author{
Nana Yaw Asabere \\ Computer Science Department \\ School of Applied Sciences and Arts \\ Accra Polytechnic, Accra, Ghana
}

\author{
Wisdom Kwawu Torgby \\ Computer Science Department \\ School of Applied Sciences and Arts \\ Accra Polytechnic, Accra, Ghana
}

\author{
Nana KwameGyamfi \\ Computer Science Department \\ Faculty of Science \\ Kumasi Polytechnic, Kumasi, Ghana
}

\begin{abstract}
As a result of the rapid proliferation of Information and Communication Technology (ICT) requirements and needs of industries and societies in both developing and developed countries, it is very important for organizations to acquire the requisite ICT manpower to substantiate such transformations. Therefore, in a developing country such as Ghana, most public and private tertiary institutions run computing related programmes in order to train both local and foreign individualsin disciplines/areas such as Computer Science (CS), ICT, IT Computer Engineering (CE) and Software Engineering (SE). Sometimes these computing related programmes are used interchangeably and confusingly as if they are synonyms, but that should not the case. From a Ghanaian perception, this paper focuses on outlining the major differences and similarities between such computing related programmes with a reflection on which public tertiary institutions in Ghana currently run them in accordance to the ICT needs and requirements of industries and societies.
\end{abstract}

\section{General Terms}

Computing Related Programmes, Public Tertiary Institutions, Ghana, Discipline, Run, Offered

\section{Keywords}

Computer Science (CS), Computer Engineering (CE), Information and Communication Technology (ICT), Information Technology (IT), Software Engineering (SE)

\section{INTRODUCTIONAND BACKGROUND OF THE STUDY The ICT} requirements and needs of industries and societies in both developed and developing countries, for example, Ghana has risen as a result of its current and rapid proliferation [1]. As a result of such needs and requirements, almost all public and private universities as well as polytechnics in Ghana offer and run computing related programmes in order to train various local and foreign individuals in disciplines/areas such as CS, CE, ICT, IT and SE [2]. Computing education in Ghana is prevalent especially at the Certificate, Diploma and Bachelor levels. Over the years, unprecedented Government investments in ICT has promoted some public and private institutions in Ghana to introduce computing education at the master's degree level. The level of $\mathrm{PhD}$ in Computing is quite scarce and only offered by institutions who affiliate with other institutions abroad. This is due to the low number of qualified staff to supervise/teach at the $\mathrm{PhD}$ research level as well as the required research facilities required to conduct research in the field of computing. Recently, the Heads of Computer Science Departments of eleven (11) public and private universities in Ghana established themselves into a Conference of Heads of Computer Science Departments, Ghana. This was after the heads met at the University of Ghana to discuss computer science education and research in Ghana. They brainstormedon approaches and tactics that can be used to address the challenges confronting, computing/IT educators and researchers in Ghana [2]. Being aware of the importance of computer science and its associated disciplines in modern-way knowledge economy settings, the heads noted that there was confusion within the profession and the general Ghanaian public regarding the difference between CS and IT as well as the other disciplines. Computer science, they said, constituted the engine that drove modern-day Information and Knowledge Economies; both as an enabler of the various sectors of the economy. A 1989 report by Denning et al. defined the field of computing as the systematic study of algorithmic processes: theory, analysis, design, efficiency, implementation and application that describe and transform information [3].

This paper elaborates on such misconceptions in the sections below. There is ample evidence to support the crucial role computer science, IT and allied disciplines have played in shaping the modern-day Information and Knowledge Economy. The heads further stated that the contribution of computing, IT and telecommunication to the Gross Domestic Product (GDP) of emerging economies such as India, Ireland, Israel and South Korea has been well documented. It is therefore crucial that public and private tertiary institutions in Ghana harness the full potential of these disciplines and their convergence with other disciplines (Bio-Informatics, Environmental Informatics etc.) for accelerated national developmental [2]. To harmonize and improve the teaching of computing related and the allied disciplines in tertiary institutions across the country, the Conference of the Heads of Computer Science Departments, Ghana resolved to work in partnership with the National Accreditation Board (NAB), the National Council for Tertiary Education (NCTE), the Committee of Vice Chancellors, the Information Technology Association of Ghana (ITAG), the Ghana Institute of Engineers (GhIE) and the Ghana Standards Authority (GSA) to adopt a common specification and curriculum. Such a specification and curriculum would not only serve as a blueprint to guide the development and implementation of computing related programmes in private and public tertiary institutions in Ghana but also serve as a reference for monitoring of computing related programmes in Ghanaian tertiary institutions by the National Accreditation Board. The Conference of the Heads of Computer Science Departments in Ghana also agreed to engage the Ministries of Communications, Education, Environment, Science and Technology and other relevant stakeholders in discussions aimed at promoting computing and Information Technology nationwide; focusing on their use to address the development challenges of Ghana and the formulation of appropriate policies [2].

According to Liu [4], computing as a discipline can be traced back to the 1960s when universities such as Stanford and CMU established computer science as a stand-alone department. The computing discipline has been vibrant since its inception. Liu [4] further emphasized that, nowadays the world operates on 
computing technologies that go beyond procedures such as desktop application, online services and daily gadgets. There is therefore a dynamic change in the emerging roles and impact of computing graduates in our society of which Ghana is not an exception. Consequently, this paper focuses on discussing, outlining and elaborating the main differences and similarities between computing related programmes offered by public tertiary institutions in Ghana in order to ascertain the actual situation on the ground. This will eradicate the confusion of the differences in computing related programmes currently being witnessed by general public of Ghana.

The rest of the paper is organized as follows. Section 2 elaborates on a brief view of relevant computing related programmes run by public tertiary institutions in Ghana. Section 3 outlines the various public tertiary institutions that are currently running/offering such programmes and which programmes in particular they are running/offering. Section 4 presents a research discussion of the paper. Section 5 concludes the paper with a recommendation.

\section{A BRIEF VIEW OF COMPUTING RELATED PROGRAMMES OFFERED BY PUBLIC TERTIARY INSTITUTIONS IN GHANA}

This section briefly describes the various computing programmes offered by public tertiary institutions in Ghana. Their similarities as well as differences are also elaborated.

\subsection{The Computer Science Programme The}

(CS)

commencements of CS as a study goesback to the 1940s, when the first digital electronic computers were developed to be used in World War II. The CS field has since seen many major accomplishments including the digital revolution and creation of the Internet, as well as the use of computers in science and mathematics [3][5].

is the study of both computer hardware and software design. It integrates both the study of theoretical algorithms and the practical problems involved in implementing them through computer hardware and software. CS is a programme/discipline that involves theory and practice as well as thinking both in abstract and tangible terms. The practical side of computing is prevalent everywhere. Nowadays, practically every person is a computer user, and many people are even computer programmers/software developers [3][5][6]. Getting computers to do what you want them to do requires thorough hands-on experience. According to Jiao and Lv [7], CS does not only give an abundant impact on the development of productive forces, but also exercises an excessive influence on the development of people's ideology as a sort of scholarly progress.

Computer

Scientists and/or CS students must be familiarizethemselves with modeling and investigative problems. They must also be able to design solutions and authenticate that they are correct. Problem solving in CS requires meticulousness, creativity, and logical reasoning. $\quad C S$ also has strong connections to other disciplines. Many problems in engineering, science, business, health care and other areas can be solved effectively with computers, but finding a solution requires both CS expertise and knowledge of the particular application domain [8]. Computer Scientists and/or CS students often become proficient in other subjects because of how computers can be used to solve problems in other domains. CS involves a range of disciplines/areas, these include: computer architecture, software systems, graphics, artificial intelligence, computer networks and software engineering. Drawing from a common core of computer science knowledge, each specialty area focuses on particular challenges [8].

CS is practiced by mathematicians, scientists and engineers. Mathematics, the origins of CS, provides reasons and logic. Science provides the methodology for learning and refinement, therefore CS study involves a lot of logical reasoning, algorithms, protocols and science [8]. The CS programme is offered at both undergraduate and postgraduate levels in Ghana. This is further elaborated in Section 3.

\subsection{The Computer Engineering (CE) Programme Tseng [9] emphasized} that Computer Engineering (CE) is the branch of engineering most directly concerned specifically with the theory and design of digital subsystems and systems of computers and their applications and also involves interfacing computers into another system to perform certain tasks. These systems may be civil, mechanical, chemical, and so forth. The computer engineer must put all the hardware together to make a computer and learn how to use it as computer scientists do. Furthermore, computer engineers write electronic/digital programs that command the computer to perform some specific tasks.

According to Tokdemir and Cagiltay [10], in CE, students start learning the fundamental perceptions of the discipline in their first year through an Introduction to $\mathrm{CE}$ courses. The topics toughed in this course can be grouped into two. In a summary, the first group includes simple concepts like binary numbering system, hard disk, memory and I/O devices. In the second group, an introduction to the courses that students will take in the next semesters of the program which includes programming, networking, software engineering, artificial intelligence and database systems. Technopedia

[11] also defines CE as a programme of study that integrates Electronic Engineering (EE) with CS to design and develop computer systems and other technological devices. CE professionals have expertise in a variety of diverse areas such as software design, electronic engineering and integrating software and hardware. CE allows professionals to engage in a number of areas such as analyzing and designing anything from simple microprocessors to highly featured circuits, software design, and Operating System (OS) development. CE is not limited to operating computer systems but is aimed at creating a broad way to design more comprehensive technological solutions [11]. CE is also known as Computer System Engineering. The CE programme is offered at both undergraduate and postgraduate levels in Ghana. This is further elaborated in Section 3.

\subsection{The Information and Communication Technology (ICT) Programme ICT} as a programme refers to the study of the technologies that provide access to information through telecommunications. It is similar to Information Technology (IT), but focuses primarily on communication technologies. This includes the internet, wireless networks, cell phones, and other communication media. Therefore, students in ICT learn more in terms of communication as compared to IT students [12]. Referring to the description of ICT by Tinio [13], in an ICT programme, students learn the diverse set of technological tools used for communication. 
Table 1: Computing Related Programmes Offered/Run by Public Tertiary Institutions in Ghana as at 19/06/2013 INSTITUTION COMPUTING PROGRAMME

\begin{tabular}{ccc}
\hline & Undergraduate & Postgraduate \\
\hline $\begin{array}{c}\text { University of } \\
\text { Ghana }^{1}\end{array}$ & $\begin{array}{c}\text { B.Sc./B.A. CS, } \\
\text { B.Sc. CE }\end{array}$ & $\begin{array}{c}\text { M.Sc. Health } \\
\text { Informatics, } \\
\end{array}$ \\
& & $\begin{array}{c}\text { MBA./M.Phil. MIS, } \\
\text { M.Eng. CE, PhD } \\
\end{array}$ \\
& & CE \\
KNUST $^{2}$ & B.Sc. CS, B.Sc. & M.Sc. IT, M.Phil. \\
& CE & CS, M.Sc./M.Phil. \\
& & CE, MBA. BIT, \\
& & PhD \\
& & \\
& & \\
& &
\end{tabular}

\begin{tabular}{|c|c|c|}
\hline $\begin{array}{l}\text { University of } \\
\text { Cape Coast } \\
(\text { UCC })^{3}\end{array}$ & $\begin{array}{l}\text { B.Sc./B.Ed. CS, } \\
\text { B.Sc./B.Ed. IT }\end{array}$ & $\begin{array}{c}\text { M.Ed. ICT, PhD CS } \\
\text { (Collaboration with } \\
\text { a Foreign } \\
\text { University) }\end{array}$ \\
\hline $\begin{array}{l}\text { University of } \\
\text { Education } \\
(\text { UEW })^{4}\end{array}$ & $\begin{array}{l}\text { B.A./B.Sc. IT } \\
\text { Education }\end{array}$ & M.Ed. ICT \\
\hline
\end{tabular}

$\begin{array}{ccc}\begin{array}{c}\text { University for } \\ \text { Development }\end{array} & \text { B.Sc. CS, B.Sc. } & - \\ \text { Studies (UDS) } & \text { IT, } & \\ \text { University of } & \text { B.Sc. CS and CE } & - \\ \text { Mines and } & \\ \text { Technology } & \\ \text { (UMaT) } & & \end{array}$

\begin{tabular}{|ccc}
$\begin{array}{c}\text { University of } \\
\text { Energy and } \\
\text { Natural } \\
\text { Resources } \\
\text { (UENR) }\end{array}$ & B.Sc. CS & \\
\hline $\begin{array}{c}\text { University of } \\
\text { Professional }\end{array}$ & $\begin{array}{c}\text { B.Sc. IT } \\
\text { Management }\end{array}$ \\
$\begin{array}{c}\text { Studies, Accra } \\
\text { (UPSA) }\end{array}$ & & \\
\hline $\begin{array}{l}\text { Ghana Institute } \\
\text { of Management } \\
\text { and Public } \\
\text { Administration } \\
\text { (GIMPA) }\end{array}$ & B.Sc. CS, B.Sc. & M.Sc. MIS, M.Sc. \\
\hline
\end{tabular}

\footnotetext{
1 www.ug.edu.gh

2 www.knust.edu.gh

3 www.ucc.edu.gh

4 www.uew.edu.gh

5 www.uds.edu.gh

6 www.umat.edu.gh

7 www.uenr.edu.gh

8 www.ips.edu.gh

9 www.gimpa.edu.gh
}

\begin{tabular}{ccc}
\hline $\begin{array}{c}\text { Koforidua } \\
\text { Polytechnic } \\
(\text { KoP })^{10}\end{array}$ & $\begin{array}{c}\text { Higher National } \\
\text { Diploma (HND) } \\
\text { CS, HND } \\
\text { Networking } \\
\text { Management }\end{array}$ & - \\
$\begin{array}{c}\text { Wa Polytechnic } \\
(\text { WP })^{11}\end{array}$ & HND CS & \\
$\begin{array}{c}\text { Kumasi } \\
\text { Polytechnic } \\
(\text { KP })^{12}\end{array}$ & HND CS, \\
$\begin{array}{c}\text { Accra } \\
\text { Polytechnic } \\
(\text { KP })^{13}\end{array}$ & HND CS \\
Wa Polytechnic \\
$(\text { WP })^{14}$
\end{tabular}

B.Sc. (Bachelor of Science), B.Ed. (Bachelor of Education), B.A. (Bachelor of Arts) M.Sc. (Master of Science), M.Phil. (Master of Philosophy), M.Ed. (Master of Education) MBA. (Master of Business Administration), $\mathrm{PhD}$ (Doctor of Philosophy) M.Eng. (Master of Engineering), PGD (Postgraduate Diploma),

Consequently, ICT students learn how to create, disseminate, store and manage information in various disciplines. The birth of ICT has enabled students to learn the combination of different technologies for effective information delivery. For example in Ghana, some of the radio stations such as Peace $\mathrm{FM}^{15}$ and Joy FM ${ }^{16}$, use both radio broadcast and computer/internet technologies (ICT) to facilitate the sharing of information to the Ghanaian and international public. Such innovations require relevant ICT professionals who have had the required training from various public tertiary institutions. The ICT programme is offered at both undergraduate and postgraduate levels in Ghana. This is further elaborated in Section 3.

\subsection{The Information Technology Programme}

involves the study of data and data processing, and may also apply to the management of computer systems, particularly in a business setting [5]. Other programmes similar to IT in business settings include Information Systems (IS) and Management Information Systems (MIS).

According to the Global Information Technology (GIT) Report [14] published by the World Economic Forum in 2012, over the past decade, the world has become increasingly hyperconnected. We live in a global world where the internet and its related services are accessible and immediate, where people and businesses can communicate with each other instantly, and where machines are equally interconnected with each other. This hyper-connectivity is deeply redefining relationships between individuals, consumers and enterprises and citizens and governments. Additionally, the GIT Report [14] emphasized that IT is introducing new opportunities but also new challenges and risks in terms of individual rights and privacy, security, cybercrime, the flow of personal dataand access to information.

\footnotetext{
10 www.koforiduapoly.edu.gh

11 www.wapoly.edu.gh

12 www.kpoly.edu.gh

13 www.apoly.edu.gh

14 www.hopolytechnic.org

${ }^{15}$ http://www.peacefmonline.com/

${ }^{16}$ http://myjoyonline.com/
} 
As a result, our economies and societies will undergo fundamental transformations and the right IT programmes are required by various developed and developing countries to meet these transformations.

When teaching in the area of IT and other computing related programmes, it is necessary to constantly update curricula, in order to deal with new challenges brought forth by students, and to modify teaching and learning methods to accommodate these new situations [15]. The IT programme is offered at both undergraduate and postgraduate levels in Ghana. This is further elaborated in Section 3.

\subsection{The Software Engineering (SE)}

Programme SE involves

the study of using sound engineering principles in order to economically obtain software that is reliable and works efficiently on machines. Usually students of SE apply systematic, disciplined and quantifiable approaches to the development operation and maintenance of software [16]. Currently, SE as a programme in public tertiary institutions in Ghana is however not common, therefore we will not discuss this programme further in this paper.

\subsection{Main Similarities and Differences between Computing Related Programmes}

\subsubsection{CS and CE}

The programme of studyCE is often confused with CS, but these two programmes are different. CS students learn hardware and software manufacturing as well asmathematics, physics, protocols and algorithms, while CE students are trained to design software and electronic systems and perform and integrate that software with hardware components. Computer engineering also includes the engineers who write firmware specifically for embedded microcontrollers, design and develop analog sensors, design very-large-scale integration chips, and create schemes for mixed- and single-circuit boards. The engineering field of CS also contributes to robotic research that requires digital systems to monitor electrical components like motors and sensors [11]. Computer scientists write programs to accomplish specified tasks and objectives. These programs are usually referred to as computer software, as opposed to the actual physical hardware devices designed by computer engineers [9].The main difference is that in $\mathrm{CE}$, there is a higher integration of electrical engineering and technologies as compared to CS which rather involves the inclusion of mathematics, physics, algorithms and some electronics.

\subsubsection{ICT and IT}

As elaborated above, ICT and IT are quite similar, the main difference between ICT and IT programmes is the additional aspect of communication technologies involved in ICT. Therefore ICT students learn more additional communication technologies/tools involving the internet, wireless networks, cell/mobile phones and other communication techniques. Current ICTs have created the opportunities for people to communicate with others across the world as if they were living next door. For this reason, ICT is often studied in the context of how modern communication technologies affect society [12]

\subsubsection{CS, CE and ICT/IT}

The CS programme is often confused with ICT/IT, but these are very different fields. IT and ICT as discussed above deals with the study of data and data processing as well as communication technologieswith respect to ICT. IT/ICT may also apply to the management of computer systems, particularly in a business setting. CS, on the other hand, deals with the more theoretical, or academic side of computing, such as algorithms, simulations and experiments. CE on another hand as elaborated above, deals mostly with the electrical/electronic aspects of computers which makes its quite close to electrical engineering and different from ICT/IT.

\section{PUBLIC TERTIARY INSTITUTIONS IN GHANA THAT RUN/OFFER COMPUTING RELATED PROGRAMMES}

This study is limited to public tertiary institutions in Ghana, consisting of Public Universities, Polytechnics and other Training Institutes. Most Private Universities in Ghana are affiliated to Public Universities. The public Universities and Polytechnics are owned and monitored by the Ghanaian Government andhave been in existence for a longer period of

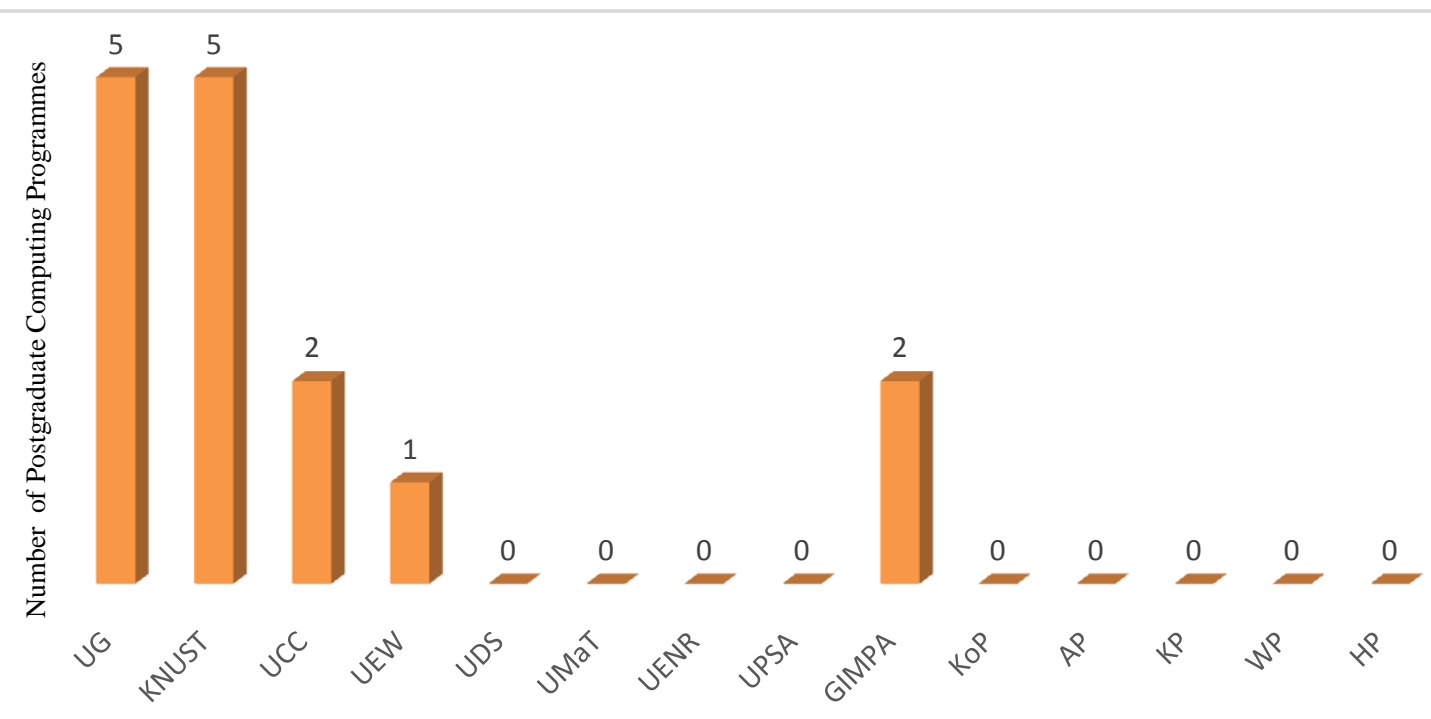

Public Tertiary Institutions in Ghana 


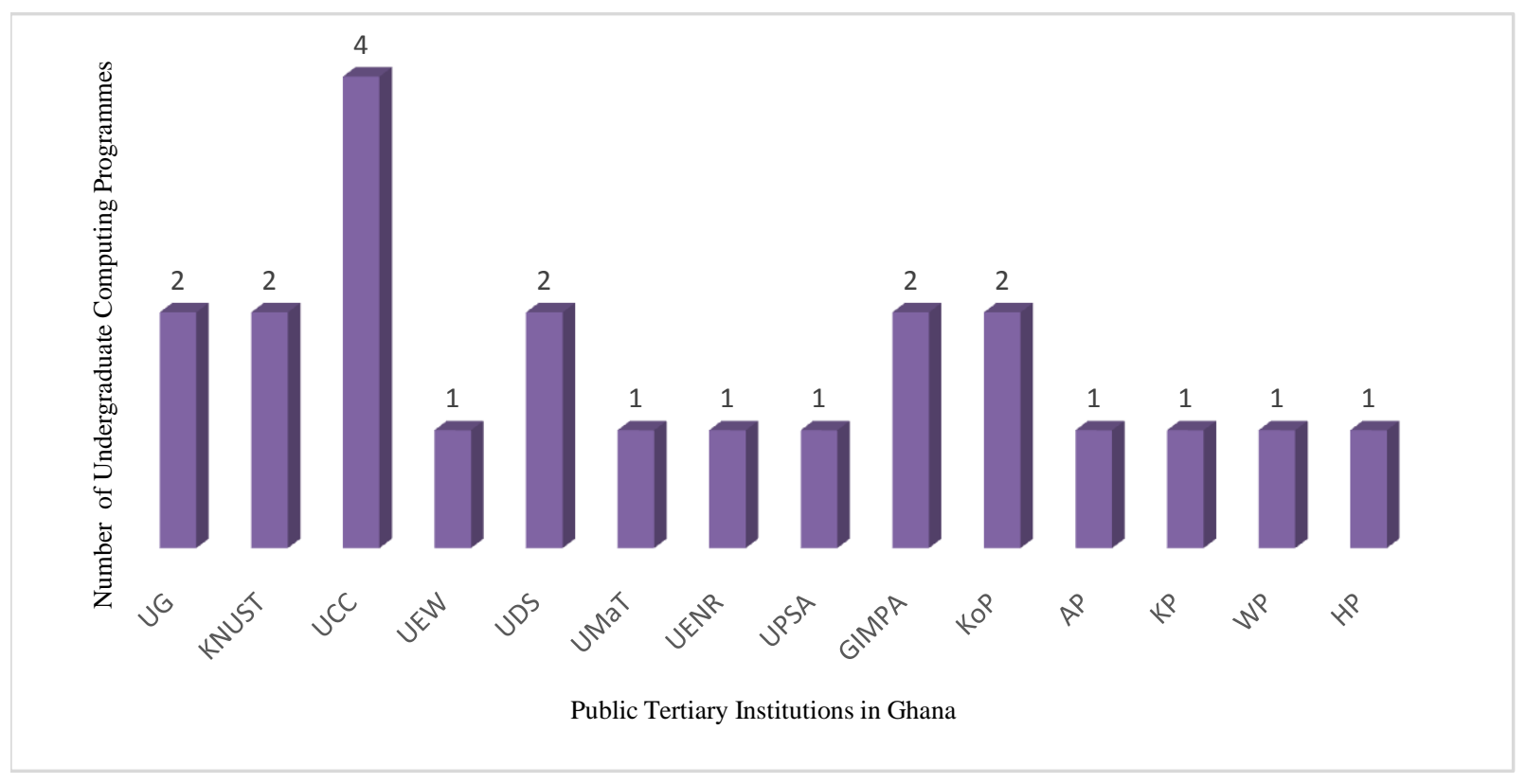

\section{Fig.2: Number of Undergraduate (BSc/BA/HND) Computing Programmes as at 19/06/2013}

time comparatively, hence theirjustification for this research. There are nine (9) public/professional universities and ten (10) polytechnics in Ghana. These can be verified in Table 1.The computing related programmes are prevalent in all public universities, however in the public polytechnics, out of the ten, five (half)of themrun these computing programmes. The origination of CS started in Kwame Nkrumah University of Science and Technology in the 1980s followed by University of Ghana, then University of Cape Coast etc. With reference to Polytechnics, Koforidua Polytechnic was the first to start running computing related programmes in 2005 , followed by the others as chronologically shown in table1.

\section{RESEARCHDISCUSSIONS}

From table 1, it is evident that all public universities and some public polytechnics in Ghana, offer/run computing related programmes, mostly at the undergraduate level which is a good sign for the Ghanaian economy.

CS at the undergraduate level (B.Sc./B.A./B.Ed./HND) is the most common and prevalent programme amongst the institutions. In terms of B.Sc., eight (8) out of the nine (9) public universities offer/run CS, the remaining public university runs/offersB.Ed. in CS which are not technically inclined as B.Sc. in terms of core CS course components. University of Cape Coast runs both B.Sc. and B.Ed. in CS, i.e. CS from an educational (graduate teachers) point of view.

Four of the Public Polytechnics

(Koforidua, Kumasi, Accra andHo) run/offer CS at the HND level and the remaining one (Wa Polytechnic) runs/offers HND ICT. Koforidua Polytechnic runs/offers another HND programme in Networking Management. Therefore in a nutshell, there are no postgraduate related to computing and no undergraduate programmes in $\mathrm{CE}$ and ITrun/offeredby the Polytechnics. Postgraduate level of education in CS (M.Phil.) is offered/run by only KNUST. IT at the undergraduate level is run/offered by University of Cape Coast, University for Development Studies and University of Professional Studies while IT in Education at the undergraduate level is run/offered by University of Education. At the postgraduate level KNUST runs/offers M.Sc. IT. In terms of IT business and health at postgraduate levels (PGD/M.Sc./MBA/M.Phil.), University of
Ghana and GIMPA offer/run programmes in Management Information Systems (MIS). KNUST offers an MBAprogramme in Business Information Technology (BIT). M.Sc. in Health Informatics, is also run/offered by the University of Ghana.

ICT at the undergraduate level in terms of B.Sc. is run by GIMPA. GIMPA also runs and MSc programme in ICT At the postgraduate level both University of Cape Coast and University of Education offer M.Ed. ICT. $\mathbf{C E}$ at both undergraduate and postgraduate levels is offered/run by only KNUST and University of Ghana i.e. B.Sc. and M.Sc./M.Phil/MEng. University of Mines and Technology combine CS and CE at the B.Sc. level. University of Ghana also runs a $\mathrm{PhD}$ programme in CE. University of Cape Coast in collaboration with a foreign University run a PhD programme. It can be realized from table 1 that KNUST and University of Ghana offer more computing related programmes at the undergraduate and postgraduate levels of education.

Referring to Figure 1, in terms of postgraduate computing programmes run/offered by the public tertiary institutions in Ghana, both UG and KNUST run/offer 5 each, UCC and GIMPA run/offer 2 each and the remaining of them currently do not run postgraduate computing programmes. With reference to the number of undergraduate computing programmes run by the public tertiary institutions in Figure 2, UCC runs/offers 4, UG, KNUST, UDS and GIMPA run/offer 2 each, UEW and UMaT, UENR and UPSA run/offer 1 each. KoP runs/offers 2 HNDs in computing and the rest of the polytechnics run/offer 1 undergraduate programme each.

According to theGhana ICT for Accelerated Development (ICT4AD) Policy [17] published in 2003, Ghana's high illiteracy rate with close to $40 \%$ of the population above the age of six years without any form of educational achievement, and only $3 \%$ of the population having tertiary level education is having serious implications on the nation's development. This presents Ghana with a challenge in terms of training individual in various tertiary programmes of which computing related programmes are not an exception. Ghana needs to promote and encourage distance education, virtual learning and e-learning so that there will be higher accomplishments achieved in term of computing related programmes at the tertiary level. 


\section{CONCLUSION AND RECOMMENDATION}

From the research discussions and analysis above, this paper can conclude that $\mathrm{CS}$ is the most dominant programme at the undergraduate level in all of the public tertiary institutions in Ghana. Other computing related programmes such as CE, ICT, IT and especially SE at both undergraduate and postgraduate levels are quite scarce and offered/run by 1-3 institutions. This means that the public tertiary institutions in Ghana are offering/running more of CS than other computing related programmes. In terms of postgraduate computing education and research in public tertiary institutions in Ghana, the turnout is very low and needs to be tackled. This paper therefore recommends that, apart from CS, public tertiary institutions in Ghana should strive to develop and update curricula for other computing related programmes, so that a monopoly is not created for CS. Such innovations will balance computing related programmes in tertiary education which will lead to the development of all the required manpower in term of computing for the society and organizations in Ghana. For effective teaching and learning of computing related programmes, this paper also recommends that the teaching staff of various computing related departments in the public tertiary institutions of Ghana should have the requisite qualifications (M.Sc./M.Phil./PhD) in CS, CE, ICT, IT and SE or their related equivalent in terms of course components and relevance. Furthermore, this paper also recommends that both public and private tertiary institutions should ensure that they develop a large pool of CS/IT/ICT/CE professionals with a wide range of state-of-the-art skills to meet the manpower needs of Ghana. Additionally, Ghana should promote world-class standards that will support nation-wide computing skills. Laws should also be enacted to involve CS/IT/ICT/CE programmes for all including women and the physically challenged and not only men. CS, CE, ICT, IT and SE educational training systems should also be linked to the Ghanaian industry and the precise training systems should be used to impart computing knowledge to students.

\section{REFERENCES}

[1] E. D. Ansong, E. A. K Affum and J. B. HayfronAcquah, "The Challenges of Young I.C.T Entrepreneur in Developing Countries: Case study Ghana," International Journal of Computer Applications (IJCA), Vol. 45, No. 21, pp. 1-4, 2012.

[2] Computer Science Heads of Public and Private Tertiary Institutions in Ghana Form Association, Available [Online]

http://ips.edu.gh/computer_heads_assoc.php(Assessed 09/05/2013)

[3] P. J. Denning, D. E. Comer, D. Gries, M. C. Mulder, A. Tucker, A. J. Turner and P.R. Young, "Computing as a Discipline," Communications of the ACM, Vol. 32, No. 1, pp. 9-23, 1989.
[4] J. Liu, "Computing as an Evolving Discipline: 10 Observations," IEEE Computer, Vol. 40, No.5, pp.112111, May 2007.

[5] The Computer Science Programme - Definition from Technopedia, Available [Online] http://www.techopedia.com/definition/592/com puter-science(Assessed 19/06/2013).

[6] P. J. Denning, "Is Computer Science Science?," Communications of ACM, Vol. 48, No. 4, pp. 27-31, 2005.

[7] Q. Jiao and H. Lv, "Cultural Function and Spiritual Value of Computer Science History and Computer

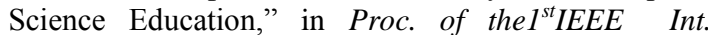
Workshop on Education Technology and Computer Science (ETCS), March 2009, pp.760-763.

[8] What is Computer Science? Available [Online] http://www.cs.mtu.edu/ john/whatiscs.html(Assessed 19/06/2013).

[9] J.H.W. Tseng, "Opportunities in Computer Engineering: Your Questions About This Dynamic Area of Specialization are Answered," IEEE Potentials, Vol. 6, No.1, pp. 12-13, Feb. 1987.

[10] G. Tokdemir and N.E. Cagiltay, "A Concept Map Approach for Introduction to Computer Engineering Course Curriculum," in Proc. of theIEEEInt.Conf.on Education Engineering (EDUCON), April 2010, pp.243-250.

[11] The Computer Engineering Programme - Definition from Technopedia, Available [Online] http://www.techopedia.com/definition/25933/computerengineering (Assessed 07/05/2013).

[12] The ICT Programme, Available [Online] http://www.techterms.com/definition/ict (Assessed 05/05/2013).

[13] V. Tinio, "ICT in Education," e-ASEAN Task Force, 2003.

[14] S. Dutta and B. Bilbao-Osorio, "The Global Information Technology Report: Living in a Hyperconnected World," World Economic Forum, 2012.

[15] B.E. Cohen, "Challenges of Information Technology Education in the $21^{\text {st }}$ Century," Idea Group Publishing, 2002.

[16] R.S. Pressman "Software Engineering - A Practitioners Approach", $5^{\text {th }}$ Edition, McGraw Hill Series in Computer Science, ISBN 0-07-365578-3, 2001.

[17] Ghana ICT for Accelerated Development (ICT4AD) Policy, 2003, Available [Online] www.nca.org.gh/downloads/Ghana_ICT4AD_Policy.pd f (accessed 19/06/2013). 